\title{
Spatial Distribution of Sensible and Latent Heat Flux in the City of Basel (Switzerland)
}

\author{
Christian Feigenwinter, Roland Vogt, Eberhard Parlow, Fredrik Lindberg, Mattia Marconcini, Fabio Del Frate, \\ and Nektarios Chrysoulakis
}

\begin{abstract}
Urban surfaces are a complex mixture of different land covers and surface materials; the relative magnitudes of the surface energy balance components therefore vary widely across a city. Eddy covariance (EC) measurements provide the best estimates of turbulent heat fluxes but are restricted to the source area. Land surface modeling with earth observation (EO) data is beneficial for extrapolation of a larger area since citywide information is possible. Turbulent sensible and latent heat fluxes are calculated by a combination of micrometeorological approaches (the aerodynamic resistance method, ARM), EO data, and GIS techniques. Input data such as land cover fractions and surface temperatures are derived from Landsat 8 OLI and TIRS, urban morphology was calculated from high-resolution digital building models and GIS data layers, and meteorological data were provided by flux tower measurements. Twenty-two Landsat scenes covering all seasons and different meteorological conditions were analyzed. Sensible heat fluxes were highest for industrial areas, railway stations, and areas with high building density, mainly corresponding to the pixels with highest surface-to-air temperature differences. The spatial distribution of latent heat flux is strongly related to the saturation deficit of vapor and the (minimum) stomatal resistance of vegetation types. Seasonal variations are highly dependent on meteorological conditions, i.e., air temperature, water vapor saturation deficit, and wind speed. Comparison of measured fluxes with modeled fluxes in the weighted source area of the flux towers is moderately accurate due to known drawbacks in the modeling approach and uncertainties inherent to EC measurements, particularly in urban areas.
\end{abstract}

Index Terms-Aerodynamic resistance method, earth observation (EO), eddy covariance (EC), GIS, urban energy budget, URBANFLUXES.

Manuscript received October 31, 2017; revised January 24, 2018; accepted February 15,2018 . This work was supported by the European Union's Horizon 2020 Research and Innovation Program under Grant 637519 (URBANFLUXES). (Corresponding author: Christian Feigenwinter.)

C. Feigenwinter, R. Vogt, and E. Parlow are with the Institute of Meteorology, Climatology, and Remote Sensing, University of Basel, Basel 4056, Switzerland (e-mail: christian.feigenwinter@unibas.ch; roland.vogt@unibas. ch; eberhard.parlow@unibas.ch).

F. Lindberg is with the Department of Earth Sciences, University of Gothenburg, Gothenburg 40530, Sweden (e-mail: fredrikl@gvc.gu.se).

M. Marconcini is with the German Remote Sensing Data Center: Land Surface German Aerospace Center (DLR), Oberpfaffenhofen 82234, Germany (e-mail: mattia.marconcini@dlr.de).

F. Del Frate is with the University Roma Tor Vergata, DICII, Rome 00133, Italy (e-mail: delfrate@disp.uniroma2.it).

N. Chrysoulakis is with the Foundation for Research and Technology - Hellas (FORTH), Heraklion GR-711 10 Greece (e-mail: zedd2@ iacm.forth.gr).

Color versions of one or more of the figures in this paper are available online at http://ieeexplore.ieee.org.

Digital Object Identifier 10.1109/JSTARS.2018.2807815

\section{NOMENCLATURE}

$\rho$

$\varepsilon$

$\triangle Q_{A}$

$\Delta Q_{S}$

$u_{*}, U$

$e_{s}^{*}, e_{a}$

$L$

$L \uparrow \downarrow$

PAR

$Q_{E, F, H}$

$r_{a}$

$\operatorname{Re}$

$R_{n}$

$r_{s \mathrm{MIN}}, r_{s}$

$T_{s}, T_{a}, T_{\mathrm{rad}}$

$z_{0 m}, z_{0 h}$

$z_{\text {ref }}, z_{d}$

Air density $\left(\mathrm{kg} \cdot \mathrm{m}^{-3}\right)$.

Emissivity dimensionless. $\left(\mathrm{W} \cdot \mathrm{m}^{-2}\right)$.

Net radiation $\left(\mathrm{W} \cdot \mathrm{m}^{-2}\right)$.
Net advective heat flux $\left(\mathrm{W} \cdot \mathrm{m}^{-2}\right)$.

Net storage heat flux $\left(\mathrm{W} \cdot \mathrm{m}^{-2}\right)$.

Friction velocity and wind velocity $\left(\mathrm{m} \cdot \mathrm{s}^{-1}\right)$.

Saturation and atmospheric vapor pressure $(\mathrm{hPa})$. Monin-Obukhov length (m).

Upwelling/downwelling longwave radiation

Photosynthetically active radiation $\left(\mathrm{W} \cdot \mathrm{m}^{-2}\right)$.

Latent/anthropogenic/sensible heat flux $\left(\mathrm{W} \cdot \mathrm{m}^{-2}\right)$.

Atmospheric resistance $\left(\mathrm{s} \cdot \mathrm{m}^{-1}\right)$.

Reynolds number (dimensionless).

(Minimum) stomatal resistance $\left(\mathrm{s} \cdot \mathrm{m}^{-1}\right)$

Surface/air/radiation temperature $(\mathrm{K})$.

Roughness lengths for momentum and heat $(\mathrm{m})$.

Reference height and zero-plane displacement height (m).

\section{INTRODUCTION}

$\mathbf{T}$ HE URBANFLUXES Horizon 2020 project (http:urbanfluxes.eu) aims to derive the Urban Energy Budget and the anthropogenic heat flux from earth observation (EO) data. Each component of the urban energy balance after [1]

$$
R_{n+} Q_{F}=Q_{H}+Q_{E}+\Delta Q_{S}+\Delta Q_{A}
$$

with the net radiation $R_{n}$, the sensible $\left(Q_{H}\right)$ and latent $\left(Q_{E}\right)$ heat flux, the storage heat flux $\Delta Q_{S}$, and the anthropogenic heat flux $Q_{F}$ being evaluated in a separate work package [2] and the net advection $\Delta Q_{A}$ is assumed to be zero. This study concentrates on the fluxes of sensible and latent heat, which are strongly modified by the properties of the urban surface, i.e., three-dimensional (3-D) geometry, high roughness, impervious surfaces, complex source/sink distribution, and injections of heat and water into the urban atmosphere by human activities (traffic, heating, waste management, etc.). The spatial variability of urban terrain complicates their estimation. The existence of various surface types and different exposures to solar radiation in a complex surface geometry leads to significant variations in heat fluxes over short distances. This problem is well known, 
TABLE I

Minimum Stomatal ResistanCES FOR LAND COVER TyPES USED IN THIS STUDY

\begin{tabular}{lc}
\hline \hline Land Cover Type & $r_{s \text { M IN }}\left(\mathrm{s} \cdot \mathrm{m}^{-1}\right)$ \\
\hline Bare soil & 500 \\
Low vegetation & 100 \\
Deciduous & 60 \\
Evergreen & 70 \\
\hline \hline
\end{tabular}

but for practical purposes, various simplifications that assume homogeneous properties at the surface like Monin-Obukhov Similarity Theory (MOST) [3] are still widely used to estimate the sensible heat flux in mesoscale models, typically with the scalar roughness approach. Although MOST was originally derived for flat and homogeneous terrain, several studies have used it over heterogeneous terrain, including cities [3].

\section{METHODS}

\section{A. Flux Calculation}

In URBANFLUXES, the Aerodynamic Resistance Method (ARM) to estimate $Q_{H}$ uses the simple relation (e.g., [4])

$$
Q_{H}=\rho c_{p} \frac{T_{s}-T_{a}}{r_{a}}
$$

where $\rho$ is the density of air, $c_{p}$ is the specific heat of air at constant pressure $\left(1005 \mathrm{~J} \cdot \mathrm{kg}^{-1} \cdot \mathrm{K}^{-1}\right), T_{s}$ is the surface temperature derived from satellite thermal infrared observations, $T_{a}$ is the air temperature recorded by the meteorological stations, and $r_{a}$ is the aerodynamic resistance. Analogously, $Q_{E}$ is expressed as

$$
Q_{E}=\frac{\rho c_{p}}{\gamma} \frac{e_{s}^{*}-e_{a}}{r_{a}+r_{s}}
$$

where $e_{s}^{*}$ is the saturation water vapor pressure at $T_{a}, e_{a}$ is the atmospheric water vapor pressure, $\gamma$ is the psychrometric constant $\left(0.67 \mathrm{hPa} \cdot \mathrm{K}^{-1}\right)$, and $r_{s}$ is the stomatal resistance. Stomatal resistance is calculated after [5] using the simplified equation from [6]

$$
\frac{1}{r_{s}}=\frac{f_{1}\left(T_{a}\right) f_{2}(\mathrm{PAR})}{r_{s \mathrm{MIN}}}+\frac{1}{r_{\text {cuticle }}}
$$

where PAR is the photosynthetic active radiation, $r_{s \mathrm{MIN}}$ is the minimum stomatal resistance, and $r_{\text {cuticle }}$ is the canopy resistance related to the diffusion through the cuticle layer of leaves $\left(10^{5} \mathrm{~s} \cdot \mathrm{m}^{-1}\right)$. Functions $f 1$ and $f 2$ are calculated as per [6] and $r_{s \mathrm{MIN}}$ can be determined for each vegetation type. $Q_{E}$ is calculated by the land cover type and weighted by the fraction of water, vegetation, and pervious surfaces with the respective $r_{s \mathrm{MIN}}$ in every pixel. Values for $r_{s \mathrm{MIN}}$ used in this study are taken from [5] and listed in Table I.

The aerodynamic resistance $r_{a}$ for sensible heat in (2) can then be written as

$$
r_{a}=\frac{1}{u_{*} k}\left[\ln \left(\frac{z_{\mathrm{ref}-z_{d}}}{z_{0 m}}\right)-\psi_{h}\left(\frac{z_{\mathrm{ref}-z_{d}}}{L}\right)+\ln \left(\frac{z_{0 m}}{z_{0 h}}\right)\right]
$$

and

$$
u_{*}=U k\left[\ln \left(\frac{z_{\mathrm{ref}-z_{d}}}{z_{0 m}}\right)-\psi_{m}\left(\frac{z_{\mathrm{ref}-} z_{d}}{L}\right)-\psi_{m}\left(\frac{z_{0 m}}{L}\right)\right]^{-1}
$$

where $u_{*}$ is the friction velocity, $k$ is the von Kármán constant $(0.4), z_{\text {ref }}$ refers to a reference height (usually the height of wind measurements), $z_{d}$ is the zero-plane displacement height, $L$ is the Monin-Obukhov length, $z_{0 m}$ is the roughness length for momentum, $z_{0 h}$ the roughness length for heat (accounting for the excess resistance when using radiometric surface temperatures [7]), and $\psi_{m, h}$ are the stability functions for momentum and heat, respectively, as documented in [8]. Equation (6) can be used to estimate $u_{*}$ from wind velocity $U$ by iteration, if no direct measurements of the friction velocity are available [9]. $z_{0 h}$ values are usually reported as the dimensionless number $k \beta^{-1}$, defined as

$$
k \beta^{-1}=\ln \left(\frac{z_{0 m}}{z_{0 h}}\right)
$$

and $z_{0 h}$ can be calculated after [4] by

$$
z_{0 h}=z_{0 m}\left(7.4 \exp \left(-\alpha \operatorname{Re}^{0.25}\right)\right)
$$

where $\operatorname{Re}$ is the roughness Reynolds number and $\alpha$ is a parameter that varies with surface. $\operatorname{Re}$ is calculated by $\operatorname{Re}=z_{0 m} u_{*} / \nu$ with a kinematic molecular viscosity $\nu$ of $1.461 \times 10^{-5} \mathrm{~m}^{2}$. $\mathrm{s}^{-1}$.

To determine the input parameters for $r_{a}$, the approach of [10] is modified to the satellite data. Both, roughness length (for heat and momentum) and displacement height are needed in $r_{a}$ calculation. Input for the calculation of roughness parameters, i.e., the morphometry, is derived from a digital surface model, including the heights of buildings and trees, in high spatial resolution (between 1 and $5 \mathrm{~m}$ ) using the open-source Geographic Information System software QGIS and the Urban Multi-scale Environmental Predictor (UMEP) [11]. UMEP output provides building heights (mean, standard deviation, maximum) and the morphological parameters plane area index and frontal area index aggregated to the chosen grid size. Roughness parameters $z_{0 m}$ and $z_{d}$ are calculated by the real urban surfaces parameterization of [12] using UMEP results as an input.

\section{B. Evaluation}

The results are evaluated by the analysis of the calculated fluxes in $100 \mathrm{~m}$ spatial resolution in the footprint of the flux towers. For $Q_{H}$ and $Q_{E}$ the source area model of Kormann and Meixner [13] is used. Fluxes are measured by the eddy covariance method and processed with standard methods [14], [15]. Since measured $Q_{H}$ and $Q_{E}$ may vary considerably between averaging intervals (normally $30 \mathrm{~min}$ ), the mean value of three half-hourly fluxes centered at overpass time was taken for the evaluation and is listed in Table II. Satellite-derived surface temperatures are compared to the surface temperature $T_{\text {rad }}$ calculated from the emitted longwave radiation in the radiation footprint of the flux towers. $T_{\text {rad }}$ is calculated by

$$
T_{\mathrm{rad}}=\left[\frac{L \uparrow-(1-\varepsilon) L \downarrow}{\sigma \varepsilon}\right]^{0.25}
$$


TABLE II

LANDSAT 8 SCENES ANALYZED FOR THE BASEL CASE STUDY AND MEASUREMENTS AT FLUX TOWER BKLI $\left(R_{\mathrm{n}}, \mathrm{RH}, w v\right.$, AND $u *$ REFER TO NET RADIATION, RELATIVE HUMIDITY, WIND VELOCITY AND FRICTION VELOCITY, RESPECTIVELY)

\begin{tabular}{lccccccc}
\hline \hline Date & $Q_{H}$ & $Q_{E}$ & $R_{\mathrm{n}}$ & $T_{\mathrm{a}}$ & $\mathrm{RH}$ & $w v$ & $u^{*}$ \\
\hline YYYYMMDD & $\mathrm{W} \cdot \mathrm{m}^{-2}$ & $\mathrm{~W} \cdot \mathrm{m}^{-2}$ & $\mathrm{~W} \cdot \mathrm{m}^{-2}$ & ${ }^{\circ} \mathrm{C}$ & $\%$ & $\mathrm{~m} \cdot \mathrm{s}^{-1}$ & $\mathrm{~m} \cdot \mathrm{s}^{-1}$ \\
\hline 20150210 & 249 & 12 & 298 & 1.7 & 32.8 & 0.85 & 0.23 \\
20150226 & 187 & 44 & 384 & 5.9 & 29.0 & 3.24 & 0.57 \\
20150314 & 176 & 16 & 413 & 5.5 & 31.7 & 1.88 & 0.46 \\
20140320 & 182 & 41 & 483 & 15.1 & 41.0 & 4.82 & 0.77 \\
20150408 & 251 & 32 & 540 & 11.3 & 22.4 & 1.07 & 0.36 \\
20150415 & 303 & 79 & 578 & 20.8 & 24.6 & 2.28 & 0.53 \\
20150424 & 300 & 96 & 596 & 17.5 & 25.6 & 1.16 & 0.37 \\
20130425 & 287 & 47 & 601 & 20.7 & 41.0 & 0.72 & 0.37 \\
20130605 & 268 & 63 & 665 & 19.3 & 52.4 & 1.14 & 0.35 \\
20140608 & 153 & 172 & 632 & 29.8 & 31.3 & 1.08 & 0.33 \\
20150611 & 367 & 44 & 639 & 23.0 & 39.7 & 0.97 & 0.41 \\
20150704 & 154 & 69 & 622 & 31.9 & 34.6 & 1.08 & 0.33 \\
20130714 & 286 & 51 & 621 & 22.7 & 51.6 & 1.19 & 0.39 \\
20140717 & 237 & 136 & 645 & 26.6 & 37.3 & 1.76 & 0.49 \\
20150805 & 251 & 69 & 612 & 25.1 & 40.7 & 1.86 & 0.44 \\
20130815 & 343 & 85 & 582 & 20.0 & 51.6 & 1.42 & 0.33 \\
20150821 & 244 & 125 & 582 & 22.1 & 36.1 & 2.00 & 0.39 \\
20150830 & 187 & 143 & 544 & 29.3 & 32.9 & 1.77 & 0.47 \\
20151001 & 192 & 42 & 404 & 9.7 & 35.0 & 3.92 & 0.59 \\
20141014 & 145 & 98 & 409 & 17.9 & 41.1 & 3.38 & 0.58 \\
20151102 & 183 & 10 & 310 & 10.2 & 43.8 & 3.37 & 0.57 \\
20151220 & 69 & 6 & 182 & 7.8 & 41.5 & 2.03 & 0.4 \\
\hline \hline
\end{tabular}

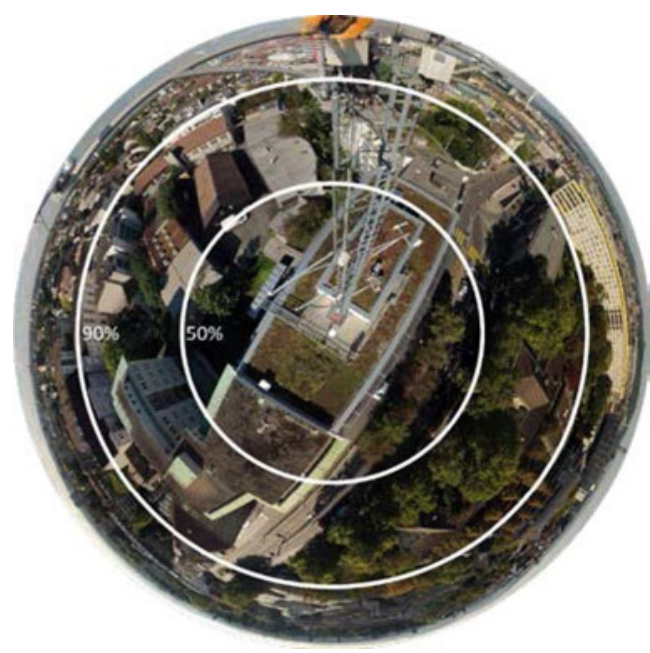

Fig. 1. Fisheye photograph from the BKLI flux tower in Basel, simulating the field of view (FOV) of the downward looking pyrgeometer. Contours refer to view factor, i.e., the percentage of received signal from the respective area (photo courtesy of M. Schmutz).

where $L \uparrow, \downarrow$ is the upwelling and downwelling longwave radiation, respectively, measured by the radiometer; $\varepsilon$ is the emissivity of the surface in the radiation footprint $(0.97)$; and $\sigma$ is the Stefan Boltzmann constant $\left(5.67 \times 10^{-8} \mathrm{~W} \cdot \mathrm{m}^{-2} \cdot \mathrm{K}^{-4}\right)$. According to [16], 50\% of the radiometer signal origins from an area below the sensor with a radius equal to the height a.g.l. of the sensor (see Fig. 1). Because the original resolution of the Landsat 8 TIRS is $100 \mathrm{~m}$ an area of $3 \times 3$ cells with the flux tower in the center was taken. The center cell was weighted $20 \%$ and the adjacent cells $10 \%$ each for the evaluation of $T_{s}$.
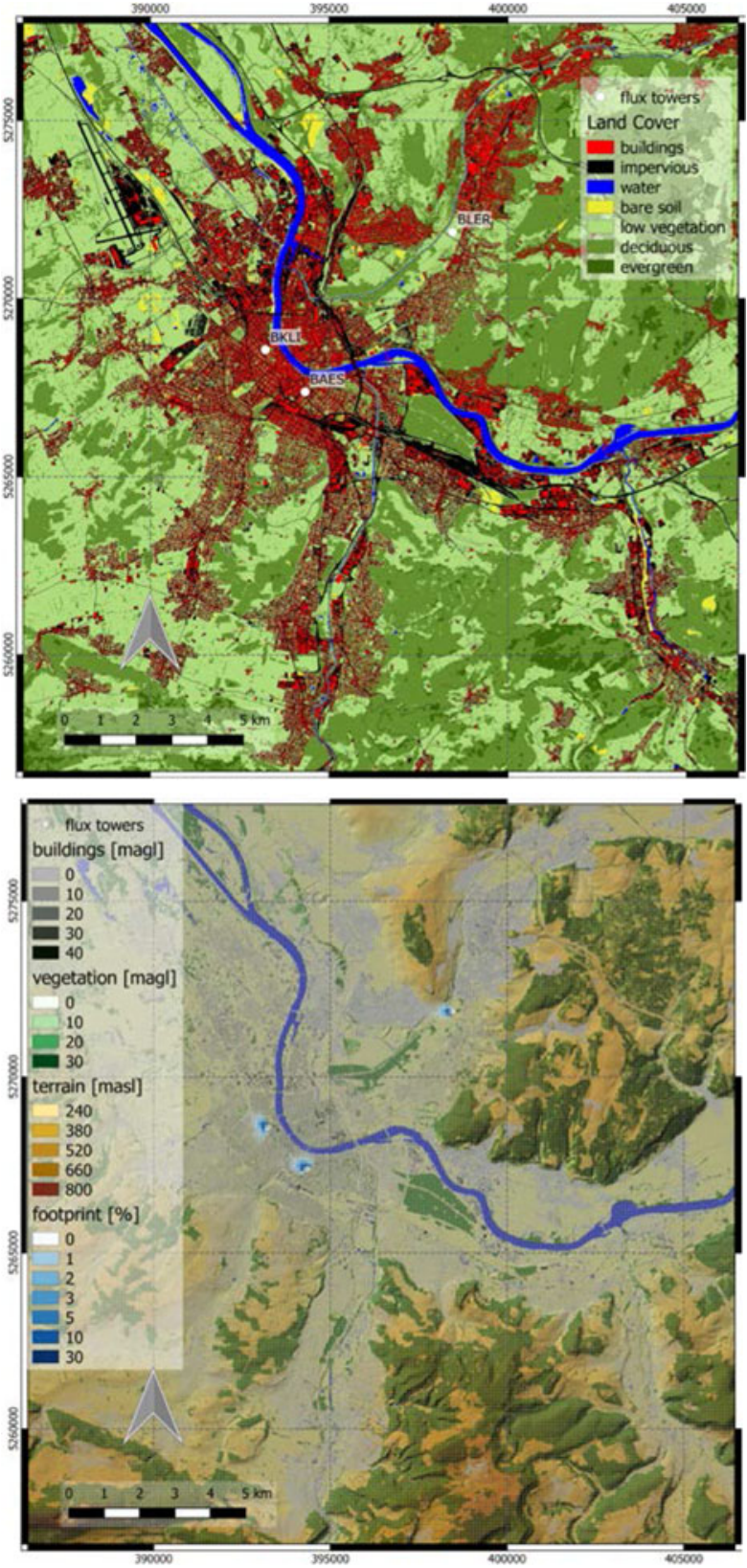

Fig. 2. Land cover map of Basel (top) and digital terrain and object model with overlayed $100 \mathrm{~m}$ grid (bottom). White points mark flux towers with footprints for August 30, 2015. Coordinate system is UTM 32 N (EPSG:32362).

\section{Study AREA AND DatASET}

Here, results from Basel (city population $200 \mathrm{k}$, Basel agglomeration population $500 \mathrm{k}$ ), a typical mid-sized mideuropean city right at the border triangle France-SwitzerlandGermany are presented. Fig. 2 shows the land cover map and the digital elevation model for the investigated area.

Land cover types (see Fig. 2) were derived from SPOT 5 data in $2.5 \mathrm{~m}$ resolution, and land cover fractions used in (4) were aggregated to the URBANFLUXES standard $100 \mathrm{~m}$ grid. Surface temperatures were calculated from Landsat 8 TIRS in the same grid using the atmospheric correction software ATCOR [17]. Urban morphology parameters used for the calculation of atmospheric resistances in (5) are available in the same 
resolution. The reference height $z_{\text {ref }}$ in (5) and (6) was taken as three times the mean building height in the $100 \mathrm{~m}$ resolution UMEP output. For the parameter $\alpha$ in (8) a value of -0.8 for built-up areas as proposed for the city of Basel in [18] and the standard value of -2.46 from [4] for areas with low roughness, i.e., mean building/vegetation height $<1 \mathrm{~m}$ (mainly the low vegetation land cover class, e.g., agricultural land use and bare soil) was applied.

$Q_{H}$ and $Q_{E}$ were calculated for 22 Landsat 8 scenes between February 2013 and December 2015 for Basel (overpass time around 11:15 UTC+1). The analyzed scenes are listed in Table II sorted by season and with the most important meteorological measurements from the BKLI flux tower (see Fig. 6) during satellite overpass. This data are used as input for evaluation of the modeled heat fluxes in Section IV-B and for the spatial extrapolation of $T_{a}$ and $u_{*}$. Because the city of Basel is surrounded by the hills of the Black Forest in the North-East and the Jura mountains in the South, measured $T_{a}$ was extrapolated to the standard grid using the dry adiabatic lapse rate of $0.0098 \mathrm{~K} \cdot \mathrm{m}^{-1}$ to consider the topography ranging from 240 to $800 \mathrm{~m}$ a.s.l. (see Fig. 2).

Friction velocity $u_{*}$ was extrapolated to the $100 \mathrm{~m}$ standard grid by iteration as in [8] using the measured wind speed and the Monin-Obukhov length $L$ at the BKLI flux tower as starting values and $100 \mathrm{~m}$ grid roughness parameters $z_{0 m}$ and $z_{d}$. Note that measurements in the same season may vary considerably between different years (see Table II) with consequences for the modeled fluxes as shown in the overview in Fig. 4. For example, $R_{n}$ on June 5, 2013, and June 8, 2014, are of similar amount (665 and $632 \mathrm{~W} \cdot \mathrm{m}^{-2}$, respectively), but the partition between $Q_{H}$ and $Q_{E}$ is completely different, namely, 268 and $153 \mathrm{~W} \cdot \mathrm{m}^{-2}$ for $Q_{H}$ to 63 and $172 \mathrm{~W} \cdot \mathrm{m}^{-2}$ for $Q_{E}$, respectively, reflecting higher $T_{a}$ and the higher saturation deficit on June 8 , 2014.

\section{RESUlTS}

\section{A. Fluxes}

Modeled sensible and latent heat flux for the Basel study area are shown in Fig. 3 for the Landsat overpass on August 30, 2015, at $1116 \mathrm{CET}$. $Q_{H}$ shows the highest values in the industrial areas, at the airport (NW of city center) and railway stations (areas with impervious land cover in Fig. 2), in the inhabited areas in the city, and in the densely populated valleys of the urban agglomeration. Negative values are calculated for River Rhine, because the surface temperature of water bodies is lower $\left(25^{\circ} \mathrm{C}\right)$ than the surrounding air temperature $\left(29^{\circ} \mathrm{C}\right)$. Dense forests also show low sensible heat flux, because the foliage temperature is close to air temperature.

Though the most important input to $Q_{H}$ in the ARM method is the difference between surface temperature and air temperature, the correlation is not always straightforward, as can be seen by the comparison of the scenes in Figs. 4 and 5. The general seasonal trend with highest fluxes for both $Q_{H}$ and $Q_{E}$ during the summer months is obvious, but interannual differences can be large when, e.g., comparing the diffent scenes available for months April, June, July, August, and October. A more detailed

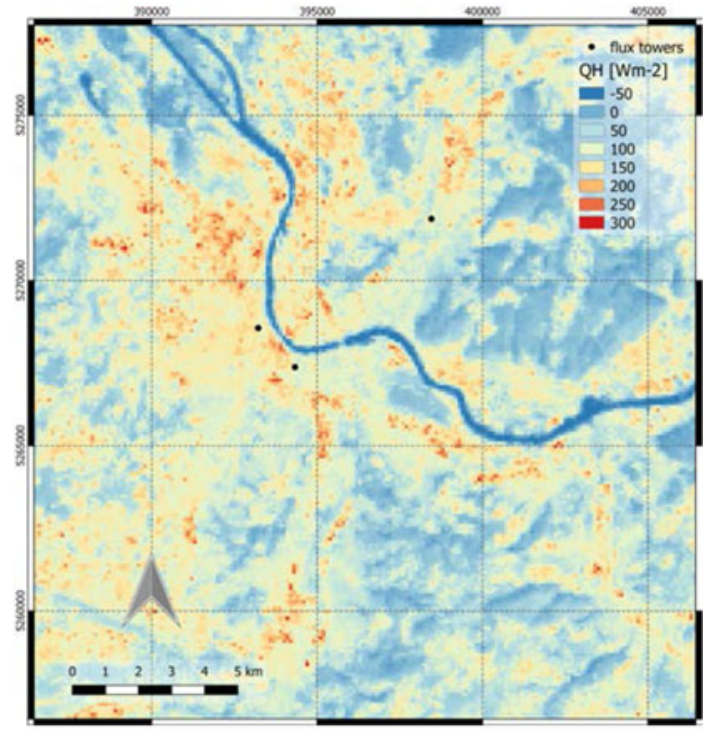

(a)

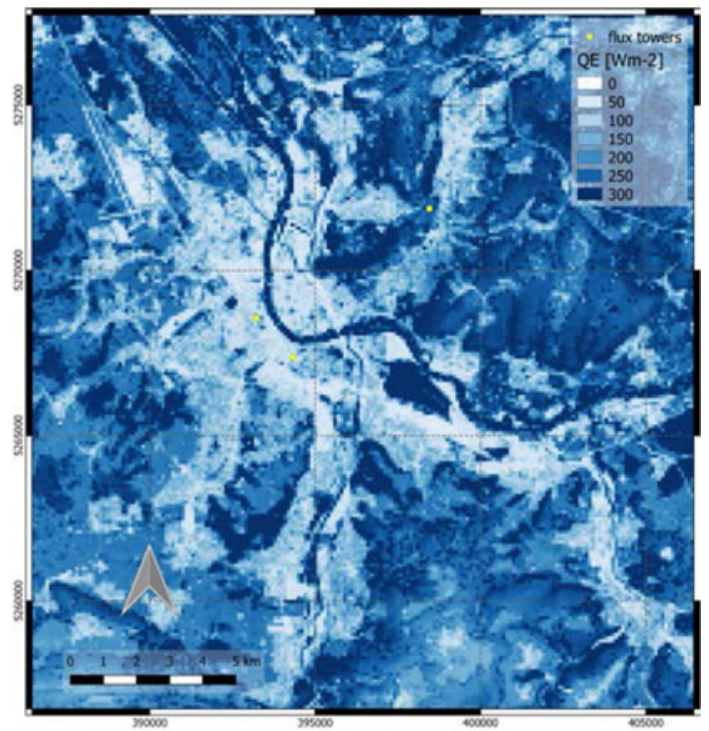

(b)

Fig. 3. (a) Sensible heat flux for Basel during Landsat 8 overpass from August 30, 2015. (b) As (a) but for latent heat flux $Q_{E}$. Black and yellow points mark flux towers BKLI, BAES, and BLER (from left to right).

analysis of the interannual variability of flux distribution and partition may raise some interesting general relations between the modeled fluxes and atmospheric conditions, but this topic is out of the scope of this paper.

\section{B. Evaluation}

Modeled $Q_{H}$ and $Q_{E}$ from the 22 Landsat scenes are evaluated by comparison with the measured fluxes in the weighted source area of the three Basel flux towers. Fig. 6 shows the locations and the weighted source areas for August 30, 2015, in the $100 \mathrm{~m}$ standard grid for Basel flux towers BKLI, BAES, and BLER with underlayed Land Cover according to Fig. 2. Note that $Q_{E}$ is not measured at BLER. 
(a)

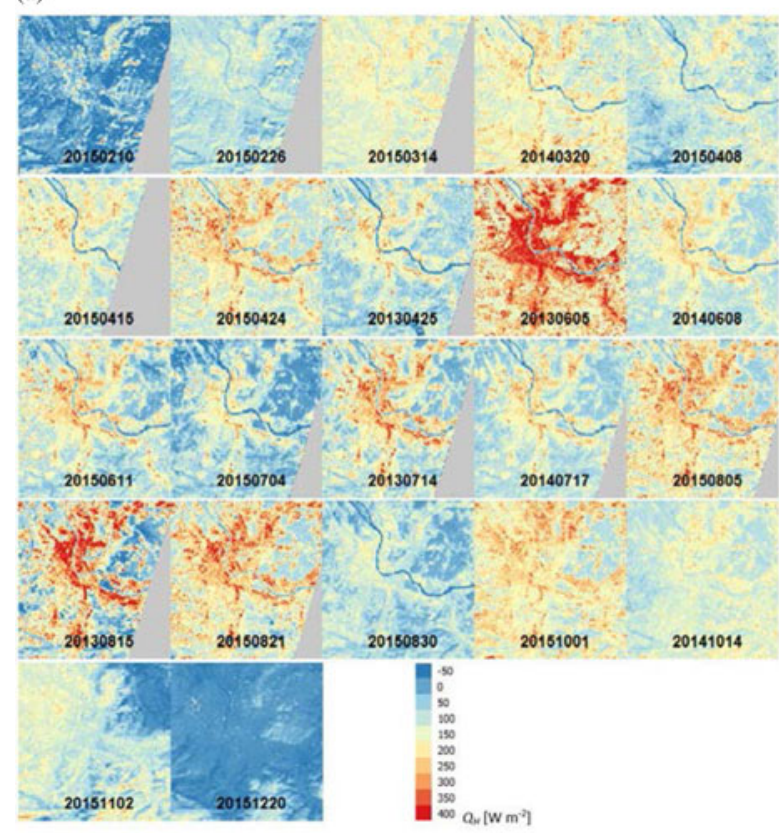

(b)

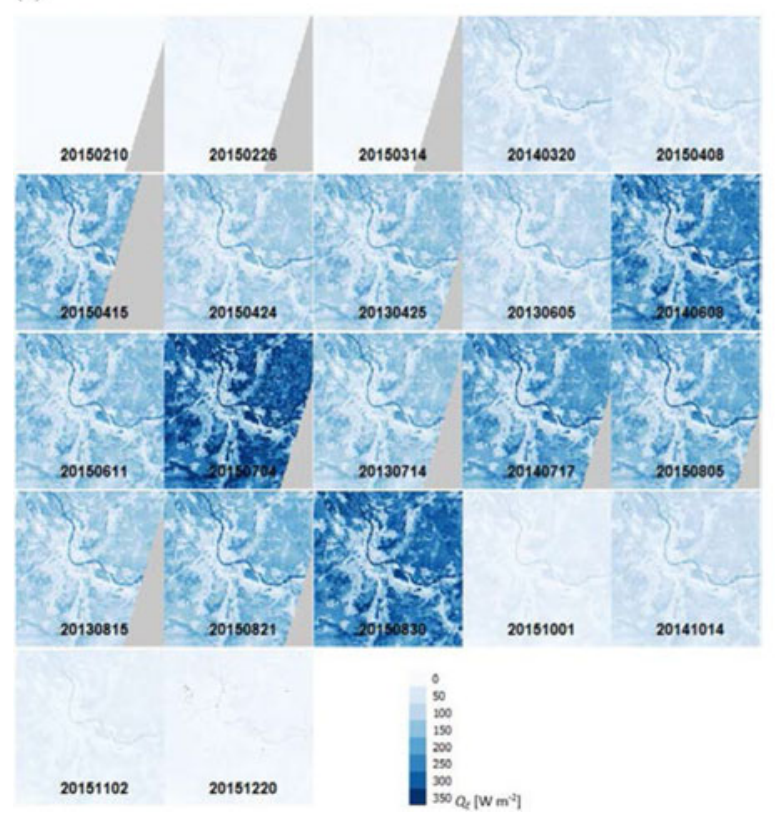

Fig. 4. (a) Sensible heat flux for 22 scenes for Basel case study (sorted by season from upper left (February) to lower right (December) according to Table II). (b) As (a) but for latent heat flux $Q_{E}$.

The regression statistics of measured to modeled fluxes and tower $T_{\text {rad }}$ to $T_{s}$ are listed in Table III and shown in Figs. 7 and 8. Agreement between measured and modeled fluxes is generally poor though flux maps in Fig. 4 show reasonable values. Modeled fluxes in the footprint of the flux towers do mostly underestimate the measured fluxes and the scatter is large.

Relative underestimation of $Q_{E}$ is larger than that for $Q_{H}$ but evaporative fluxes are of course lower in urban areas than in the rural surroundings.

Regression statistics for $T_{s}$ are better than that for the heat fluxes; nevertheless, differences may reach up to $4 \mathrm{~K}$ (see Fig. 8).

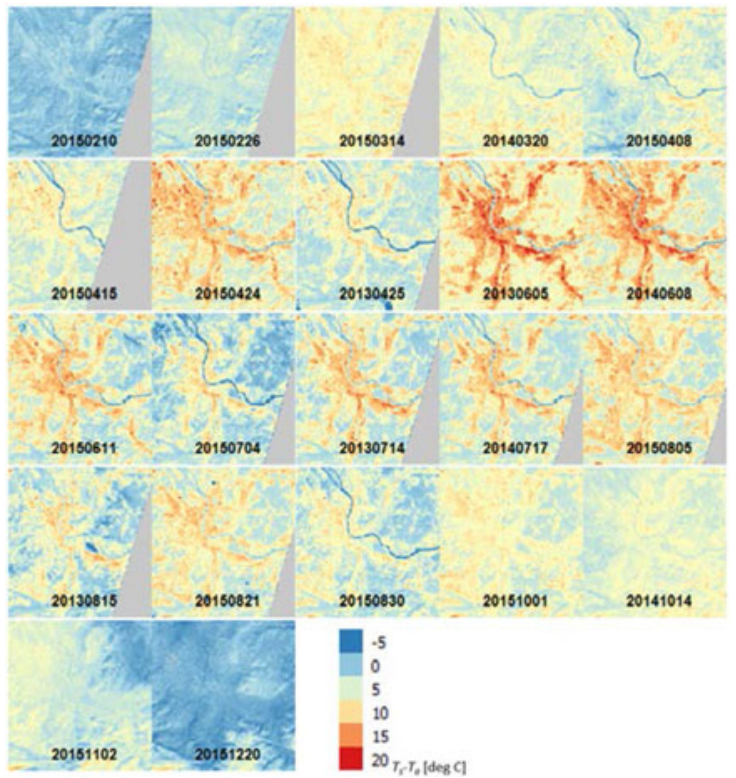

Fig. 5. As Fig. 4 but for temperature difference $T_{s}-T_{a}$.
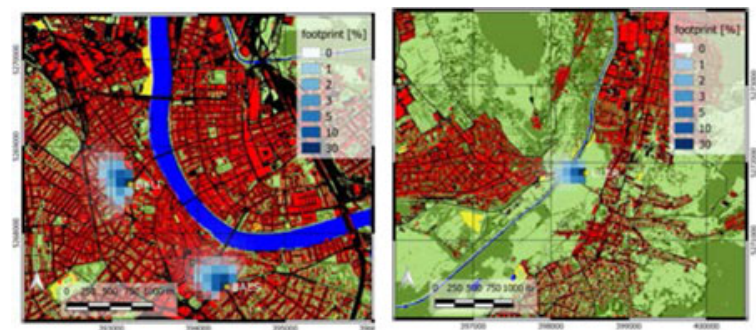

Fig. 6. Weighted footprints for August 30, 2015, satellite overpass (11:00 UTC+1). Left: Urban flux towers BKLI and BAES. Right: Rural/suburban flux tower BLER. Reference system is UTM 32N.

TABLE III

REgRESSION STATISTICS FOR $T_{S}, Q_{H}$, AND $Q_{E}$ AT FLUX TOWERS

\begin{tabular}{lcccc}
\hline \hline Flux Tower & Slope & Offset & $R_{2}$ & RMSE \\
\hline Surface Temperature & & & & $\mathrm{K}$ \\
\hline BKLI & 1.09 & -27.81 & 0.988 & 1.7 \\
BAES & 1.09 & -25.98 & 0.987 & 1.8 \\
BLER & 0.95 & 10.6 & 0.987 & 1.5 \\
Total & 1.03 & -11.42 & 0.963 & 2.9 \\
\hline Sensible heat flux & & & & $\mathrm{W} \cdot \mathrm{m}^{-2}$ \\
\hline BKLI & 0.76 & 10.95 & 0.63 & 66 \\
BAES & 0.92 & -17.97 & 0.68 & 57 \\
BLER & 0.58 & 40.60 & 0.63 & 34 \\
Total & 0.76 & 15.88 & 0.71 & 54 \\
\hline Latent heat flux & & & & $\mathrm{W} \cdot \mathrm{m}^{-2}$ \\
\hline BKLI & 0.58 & 16.00 & 0.65 & 30 \\
BAES & 0.42 & 13.34 & 0.64 & 18 \\
Total & 0.54 & 12.76 & 0.65 & 25 \\
\hline \hline
\end{tabular}

Satellite-derived $T_{s}$ are higher at the urban flux towers BKLI and BAES and lower at the rural/suburban flux tower BLER. This is addressed to the different fields of view, i.e., the radiation sensor mounted on an urban flux tower "sees" a considerable amount of walls (see Fig. 1), which are more influenced by shadow 


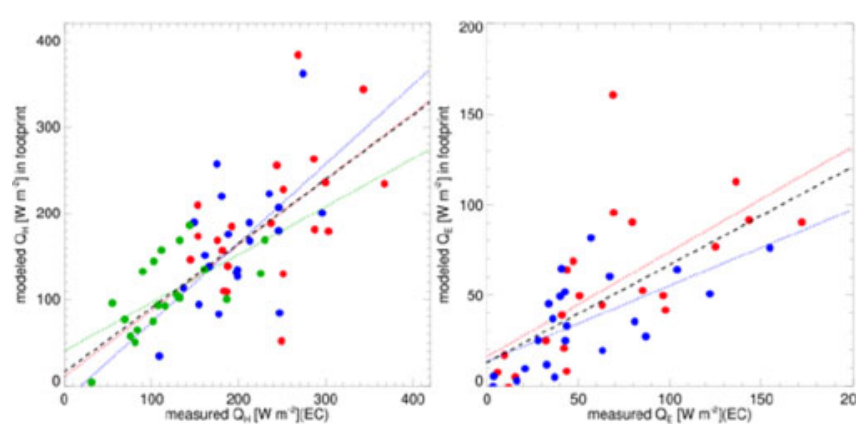

Fig. 7. Comparison of modeled ( $y$-axis) and measured ( $x$-axis) $Q_{H}$ (left) and $Q_{E}$ (right) for flux towers BKLI (red), BAES (blue) and BLER (green).

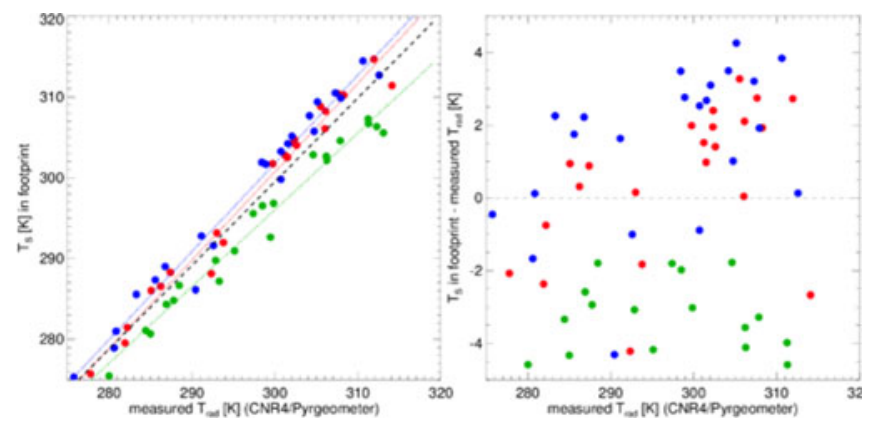

Fig. 8. Left: Measured surface temperature $T_{\text {rad }}$ ( $x$-axis) against satellitederived surface temperature $T_{s}$ ( $y$-axis) in the radiation footprint of flux towers BKLI (red), BAES (blue), and BLER (green) with regression lines. Black dashed line is the regression for all data. Right: Same as left panel, but for the differences $T_{s}-T_{\text {rad }}$.

effects and may lead to cooler $T_{\text {rad }}$. Additional uncertainty is introduced by the use of a bulk emissivity for EO-derived $T_{s}$ and atmospheric correction.

\section{Sensitivity Analysis}

A sensitivity analysis was performed in order to estimate the influence of the input variables on the value of modeled $Q_{H}$. A perturbation of $T_{s}$ [or $\left(T_{s}-T_{a}\right)$ in (2)] by $\pm 2 \mathrm{~K}$ causes a change in $Q_{H}$ in the range of $\pm 50 \mathrm{~W} \cdot \mathrm{m}^{-2}$. A change in friction velocity $u_{*}$ of $20 \%$, i.e., a variation in the range of $0.05-0.15$ $\mathrm{m} \cdot \mathrm{s}^{-1}$, impacts the value of $k \beta^{-1}$ and $r_{a}$ and affects $Q_{H}$ by $\pm 25 \mathrm{~W} \cdot \mathrm{m}^{-2}$. And finally, an increase/decrease of the roughness parameters $z_{0}$ and $z_{d}$ by $20 \%$, corresponding to a variation of the original values in the range of $0.1-0.4 \mathrm{~m}$ for $z_{0}$ and $2-6 \mathrm{~m}$ for $z_{d}$, results in a change in $Q_{H}$ of $\pm 10 \mathrm{~W} \cdot \mathrm{m}^{-2}$. In line with $Q_{H}$, the term $\left(e *-e_{a}\right)$, i.e., the water vapor pressure deficit, is most crucial for the value of $Q_{E}$, for vegetated surfaces the value of $r_{s}$ (mainly determined by the specific $r_{s \text { MIN }}$ ) has a similar impact. However, compared to the variations in $Q_{H}$ and considering the generally low values of $Q_{E}$ in urban environments, the impact of variations of input variables in (3) is generally small for the urban energy balance.

\section{DISCUSSION AND OUTLOOK}

The analysis of modeled $Q_{H}$ and $Q_{E}$ from 22 Landsat scenes for the URBANFLUXES case study city Basel shows reasonable results, but the validation with in situ measurements is generally moderately accurate. Since there is no alternative for the evaluation of EO-derived fluxes, possible reasons for the observed deviations are listed in the following:

1) The uncertainty inherent to EC measurements may range from $10 \%$ for $Q_{H}$ to up to $25 \%$ for trace gases (e.g., [19], [20]). Representativeness of flux tower measurements in urban environments is reduced compared to rural areas due to the heterogeneity of urban neighbourhoods [14]. Large (inherent) variations in EC measurements between averaging intervals additionally increase this uncertainty. Using averages of the adjacent half hours (before and after the satellite overpass) for comparison with modeled fluxes reduce this uncertainty.

2) Known drawbacks of the ARM method: input parameters $\left(T_{a}, w v\right)$ have to be spatially derived from in-situ measurements (flux towers and/or sensor networks) and may differ from "true" values in certain areas during satellite overpass; further large uncertainties exist in the calculation of the aerodynamic resistance including $k \beta^{-1}$.

3) Uncertainties in the calculation of flux tower source areas used for comparison with modeled fluxes [21].

4) Difficulties to measure evapotranspiration in general and in urban areas in part. Spatial extrapolation of measured vapor saturation deficit.

Finally, modeled fluxes may be in a first step improved by examination of uncertainties in $T_{s}$ related to emissivity, thermal anisotropy and atmospheric correction in urban areas.

As URBANFLUXES will model all terms of the urban energy balance independently to derive the anthropogenic heat flux as a residual, the presented results are combined with EO-derived storage term $\Delta Q_{S}$ and net radiation $R_{n}$ towards analyzing the energy balance closure (including $Q_{F}$ ) in the framework of this project.

\section{ACKNOWLEDGMENT}

The authors would like to thank the reviewers for their comments.

\section{REFERENCES}

[1] T. R. Oke, G. Mills, A. Christen, and J. A. Voogt, Urban Climates. Cambridge, U.K.: Cambridge Univ. Press, 2017.

[2] N. Chrysoulakis et al., "anthropogenic heat flux estimation from space: Results of the second phase of the URBANFLUXES Project," in Proc. Joint Urban Remote Sens. Event, Dubai, UAE, Mar. 30-Apr. 1, 2017 (978-1-5090-5808-2/17/ 31.00 C2017 IEEE).

[3] T. Foken, "50 years of the Monin-Obukhov similarity theory," Boundary Layer Meteorol., vol. 119, pp. 431-447, 2006.

[4] W. Brutsaert, Evaporation Into the Atmosphere. Boston, MA, USA: D. Reidel Publ., 1982.

[5] S. Kato and Y. Yamaguchi, "Estimation of storage heat flux in an urban area using ASTER data," Remote Sens. Environ., vol. 110, pp. 1-17, 2007.

[6] K. Nishida, R. R. Nemani, S. W. Running, and J. M. Glassy, "An operational remote sensing algorithm of land surface evaporation," J. Geo. Res, vol. 108(D9), 4270, 2003, doi: 10.1029/2002JD002062.

[7] J. A. Voogt and C. S. B. Grimmond, "Modeling surface sensible heat flux using surface radiative temperatures in a simple urban area," J. Appl. Meteorol., vol. 39, pp. 1679-1699, 2000.

[8] U. Högström, "Non-dimensional wind and temperature profiles in the atmospheric surface layer: A re-evaluation," Topics in Micrometeorology. A Festschrift for Arch Dyer. Dordrecht, The Netherlands: Springer, 1988, pp. 55-78. 
[9] C. S. B. Grimmond and H. A. Cleugh, "A simple method to determine Obukhov Lengths for suburban areas," J. Appl. Meteorol., vol. 33, pp. 435440, 1994.

[10] D. F. Nadeau et al., "Estimation of urban sensible heat flux using a dense wireless network of observations," Environ. Fluid Mech., vol. 9, pp. 635653, 2009.

[11] F. Lindberg et al., "Urban multi-scale environmental predictor (UMEP) An integrated tool for city-based climate services," Env. Modell. Softw., vol. 99, pp. 70-97, 2018.

[12] M. Kanda, A. Inagaki, T. Miyamoto, M. Gryschka, and S. Raasch, "A new aerodynamic parametrization for real urban surfaces," Boundary-Layer Meteorol., vol. 148, pp. 357-377, 2013.

[13] R. Kormann and F. X. Meixner, "An analytical footprint model for nonneutral stratification," Boundary-Layer Meteorol., vol. 99, pp. 207-224, 2001.

[14] C. Feigenwinter, R. Vogt, and A. Christen, "Eddy covariance measurements over urban areas," in Eddy Covariance A Practical Guide to Measurement and Data Analysis. Heidelberg, Germany/New York, NY, USA: Springer Atmospheric Sciences, 2012, ch. 16, pp. 377-397, p. 430.

[15] X. Lee, W. Massman, B. Law, Eds., Handbook of Micrometeorology. Heidelberg, Germany/New York, NY, USA: Springer, 2005.

[16] W. E. Reifsnyder, "Radiation geometry in the measurement and interpretation of radiation balance," Agr. Meteorol., vol. 4, pp. 255-265, 1967.
[17] R. Richter and D. Schläpfer, ATCOR-2/3 User Guide, Version 9.0.0. DLR, ReSe Applications, Switzerland, 2015.

[18] C. M. Frey and E. Parlow, "Determination of the aerodynamic resistance to heat using morphometric methods," EARSel eProc., vol. 9, no. 2, pp. 52 63, 2010.

[19] J. Wang, J. Zhung, W. Wang, S. Liu, and Z. Xu, "Assessment of uncertainties in eddy covariance flux measurements based on intensive flux matrix of HiWATER-MUSOEXE," IEEE Geos. Rem. Sens. Lett., vol. 12, no. 2, pp. 259-263, Feb. 2015.

[20] A. D. Richardson et al., "Uncertainty quantification," in Eddy Covariance - A Practical Guide to Measurement and Data Analysis. Heidelberg, Germany/New York, NY, USA: Springer Atmospheric Sciences, 2012, pp. 173-207, p. 430.

[21] A. Hellsten et al., "Footprint evaluation for flux and concentration measurements for an urban-like canopy with coupled Lagrangian stochastic and LES simulation models," Bound.-Layer Meteorol., vol. 157, pp. 191$217,2015$.

Authors' photographs and biographies not available at the time of publication. 